\title{
The Impact of New Electricity Reform on the Management of Power Network Investment Planning and Its Countermeasures
}

\author{
Cui Kai ${ }^{1}$, Zhao Juan $^{1}$, Wu Xiao ${ }^{2}$, Li Hui ${ }^{3,}$, Tian Yanhua ${ }^{3}$, and Li Jing ${ }^{3}$ \\ ${ }^{1}$ State Grid Economic and Technological Research Institute Co., Ltd., 102209 Beijing, China \\ ${ }^{2}$ State Grid Tianjin Electric Power Company Economic Research Institute, 300171 Tianjin, China \\ ${ }^{3}$ Tianjin Tianda Qiushi Electric Power High Technology Co.,Ltd., 300384 Tianjin, China
}

\begin{abstract}
A new round of power system reform will gradually promote the construction of power market in China. In this process, many policies will have an impact on the investment plan management of power grid enterprises. Firstly, this paper analyses the basic framework of China's new power reform and two key tasks affecting grid investment. Then, the impact of electricity reform policy on investment decision-making of power grid is analyzed, including investment planning objectives, planning principles, planning depth, planning effectiveness and investment management. Finally, the investment plan management strategy of power grid company under the new situation is put forward.
\end{abstract}

\section{Introduction}

On March 15, 2015, the promulgation of Several Opinions on Further Deepening the Reform of Electric Power System marked the beginning of a new round of electric power system reform in China [1]. The influence of power system reform on power grid enterprises is multifaceted. From the perspective of regulatory authorities, under the cost-plus pricing method, grid companies have potential incentives to overinvest, so grid investment will be more strictly regulated by the government in the future, and the investment autonomy of grid companies will be weakened, but it is still in the transitional period [2]. At the same time, at this stage, the valid assets verification process and operating rules are not clear, the boundary conditions are not clear, and there are greater risks [3]. Strong supervision of income and cost will also affect the cash flow of power grid companies, while the investment of transmission and distribution assets requires a large amount of capital, which may increase certain financial costs. In addition, in terms of distribution network planning and investment, orderly liberalization of distribution and distribution business to social capital and gradually liberalization of incremental distribution investment business to eligible market players will diversify the main components of distribution network planning and construction, thus increasing the difficulty of unified planning and orderly construction of distribution network $[4,5]$.

Based on the analysis of the task framework of the new power reform, this paper studies the impact of the new power reform on the management of the power grid investment plan. Thus, the adaptive strategy of power grid investment management is formulated, which provides theoretical guidance for the practice of power grid investment planning management.

\section{Task Framework of New Power Reform in China}

The reform policy of electric power system clearly points out the reform focus and basic path of "three liberalization, three strengthening and one independence", and the system framework design of "two liberalization and control of the middle". The reform includes six key tasks: power market construction, independent power trading institutions, transmission and distribution price verification, power generation plan liberalization, distribution and distribution market liberalization, and orderly development of self-owned power plants. Among the key tasks, the liberalization of transmission and distribution prices and the liberalization of distribution and distribution market will have a greater impact on the investment planning of power grid.

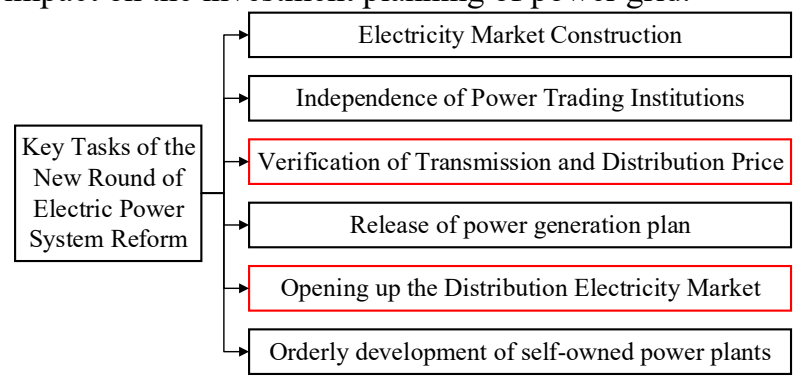

Fig. 1. Task Framework of New Power Reform.

In the aspect of transmission and distribution price reform, the profit of power grid enterprises will change from the current "purchase-sale price gap" mode to

\footnotetext{
*Corresponding author: 1718241359@qq.com
} 
"cost-plus-profit" mode. The government's supervision of power grid enterprises will be transformed from the indirect supervision of the current two-end price of purchase and sale of electricity and the differential income of power grid enterprises to the direct supervision of all-round transmission and distribution revenue, cost and price based on the effective assets of power grid.

In terms of opening up the distribution market, the core business of power grid enterprises in the future is to undertake the bottom-guaranteed power supply services in their power supply business areas, to ensure the electricity consumption of residents, agriculture, important public utilities and public welfare services. According to the definition in the supporting documents, after the liberalization of the electricity market, the power grid enterprises may include new operators of the incoming distribution network formed by mixed ownership, in addition to the traditional power grid enterprises such as the State Grid Corporation and the Southern Grid Corporation. If the new distribution network operators are unable to perform their duties due to some reasons, the state-owned power grid enterprises will perform their duties on their behalf.

\section{The Impact of New Power Reform on the Comprehensive Planning Manage- ment of Power Grid Investment}

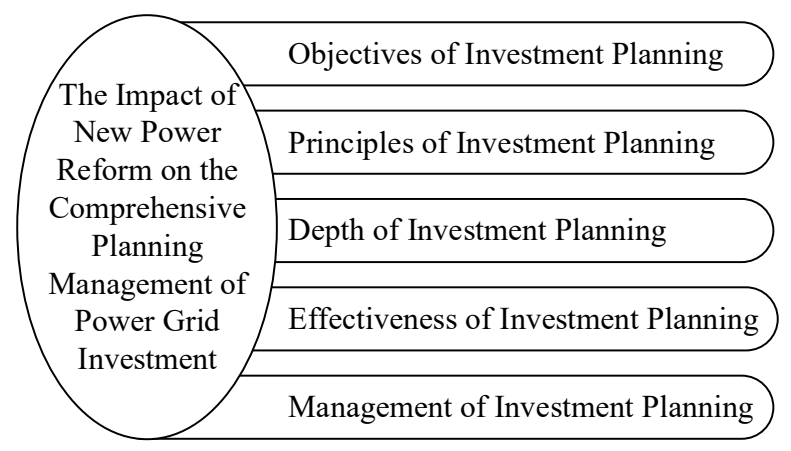

Fig. 2. The Impact of New Power Reform on the Comprehensive Planning Management of Power Grid Investment.

\subsection{The Impacts on the objectives of power grid investment planning}

Under the reform of electric power system, power grid planning will really return to its original position and play a guiding role. Power grid enterprises should embody the attributes of public utilities, meet the demand of power supply, pay attention to improving the safety and reliability of power grid operation, and play the role of "supply and demand" as a bridge. We also need to actively play a guiding role in coordinating with the reasonable incremental distribution business and electricity sales business operated by other main bodies, with the corresponding planning channels and interfaces, and for the business with hidden dangers or irregularities, we should eliminate them in the planning period. Power grid enterprises need to do a good job of coordination among enterprises, governments and upstream and downstream industrial chains. In this way, the planning plan and project can be landed by integrating multi-agent needs. Under the original system, the goal of power grid planning is mainly to meet the needs of regional power supply and business development of power grid companies. The degree of autonomous decision-making of power grid planning is relatively high. This power system reform plans to introduce market mechanism in the development, distribution and sale links, which will increase the uncertainties faced by power grid planning, and bring great challenges to the design and Realization of planning objectives.

\subsection{The Impacts on the Principles of Power Network Planning}

The new environment formed after the reform of electric power system has brought certain influence to the goal of power grid planning, and the corresponding planning principles will also be adjusted. The main manifestations are as follows: 1) The planning scheme should embody the principles of high quality service and green low carbon. The orientation and attributes of power grid enterprises are clearly defined in the document of power system reform, and the important position of renewable energy is emphasized. In the planning process, we must consider how to reflect the reform requirements and achieve the reform objectives. Therefore, the above principles should be taken seriously. 2) The planning principle has changed from safety and reliability to flexibility and reliability. Opening up the user-side distributed generation market in an all-round way and allowing all kinds of distributed generations to access the distribution network increase the uncertainty of the distribution network structure, and put forward higher requirements for the flexibility and robustness of the network planning. 3) The future power grid planning involves a variety of subjects and modes of cooperation, which requires an open attitude and embodies the principle of sharing and integration. The government encourages private capital to participate in this round of reform. Power grid construction and planning are no longer solely responsible for power grid enterprises, but are jointly participated by multiple investors. The economic choice of planning objective function and the determination of constraints need to reflect the interests of all investors, which puts forward higher requirements for the coordination of distribution network planning.

\subsection{The Impacts on the Depth of Power Network Planning}

For the depth of planning, the following three points need to be paid attention to: first, the accuracy of distributed generation output prediction and multi-user load forecasting; second, the screening and evaluation of risk factors; the reform makes the market structure more complex, the market subject more diversified, the trading mode more diverse, the trading commodities more 
abundant, and the market risk, policy risk and financial risk are also increased along with it; Compatibility of planning schemes, future power grid planning will gradually separate from the separate planning mode, and will be integrated with other energy planning and urban planning, but this integration may increase the constraints of power grid planning, or even change the content of the objective function, so the research in this area also needs to be paid attention to.

\subsection{The Impacts on the Effectiveness of Power Network Planning}

On the one hand, the reform of transmission and distribution price and the liberalization of distribution and distribution market will stimulate grid enterprises to plan ahead and invest ahead to seize the market to a certain extent; on the other hand, the orientation and supervision mode of power reform policy for grid enterprises require them to invest reasonably and effectively, and planning safety standards will also control their over-investment and unnecessary investment. Therefore, whether the planning project can be approved by the relevant regulatory authorities is crucial to turn the enterprise assets into "effective assets". Therefore, the investment planning of power grid enterprises in the reform of electric power system must take a lean approach, from the aspects of setting planning objectives and principles, coordinating planning plans, optimizing investment scale and structure, and comprehensive risk assessment, to ensure that planning projects are recognized by regulatory authorities and that planning projects are effectively landed.

\subsection{The Impacts on Investment Management of Power Grid}

The reform of the current round of power system involves a wide range of aspects. The intention of introducing market mechanism into the development, distribution, sale, price and other links is clear, which has brought an impact on the investment management of power grid. On the market side, as the attribute of stateowned public utilities, Guangzhou Power Supply Bureau needs to bear the guarantee of the bottom line, and indirectly bears the risk of project investment construction and operation brought by the introduction of private enterprises. In addition, the market has joined a large number of multi-stakeholders, especially some private capital, whose capital flows quickly, operation process is relatively simple, and some enterprises have certain influence in the local community, so they can quickly enter the market to invest and seize high-quality resources, which has a great impact on the business of power grid enterprises.

\section{Adaptability Strategy of Power Grid Investment Planning Management under New Power Reform}

\subsection{Improving the Method of Power Network Planning}

The traditional planning method mainly considers the load demand, takes the reliability of power supply as the standard, and plans and constructs the distribution network by satisfying the demand side power demand. With the implementation of the new electricity reform, it is no longer applicable to single consideration of meeting the demand side of the power demand. The development of distributed generation and the increase of new loads such as electric vehicles will bring new difficulties to the distribution network planning, and also put forward higher requirements for the distribution network planning. These new factors are random and intermittent, and need to be dealt with by uncertainty method. Many literatures adopt chance-constrained programming to deal with the randomness of distributed generation output [6]. Compared with the traditional method, which requires the planning scheme to satisfy all constraints under any conditions, chance-constrained programming uses the idea of probability. At the same time, by combining chance-constrained programming with reliability analysis, the planning cost can be reduced on the premise of certain reliability.

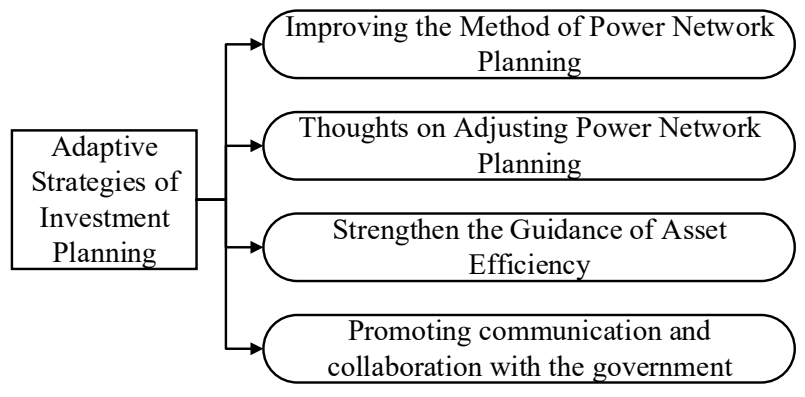

Fig. 3. Adaptability Strategy of Power Grid Investment Planning Management under New Power Reform.

\subsection{Thoughts on Adjusting Power Network Planning}

In the new market environment, power grid planning is essentially more to provide decision-making reference scheme from a professional point of view under the boundary conditions and standards given by the government, and to recommend it to the government and the public through professional argumentation, so as to guide the government and the public to recognize the development ideas and development lines of power grid companies. In this process, power grid companies should give full play to their professional and technical advantages, combine with relevant government requirements and standards, do a good job of professional demonstration in the planning process, help the government to do a good job of local power grid planning, while striving for a certain space for independent decision-making for power grid companies, and guide the government to make scientific decisions on power grid planning. Under the guidance of the new policy, the primary goal of power grid development is to meet the normal power supply needs of users. That is to 
say, in planning project arrangement, priority should be given to ensuring the power supply of all users within the power supply scope, meeting the basic requirements of countries and industries such as unlimited power supply, unrestricted reporting and voltage quality stability, and paying attention to the solution of existing problems of power grid in order to promote the overall and balanced development of power grid.

\subsection{Strengthen the Guidance of Asset Efficiency}

After the implementation of the electricity reform policy, the economy of power grid construction and the utilization efficiency of power grid assets will be supervised by the government, which puts forward higher requirements for the planning and development of power grid companies, asset management and investment control capabilities. Firstly, we should clarify the category of effective assets as soon as possible, strive for the historical cost base to the greatest extent, upgrade the level of operation and maintenance of equipment assets, strengthen the life cycle management of assets, and reduce the operation and maintenance costs. Secondly, we should improve the depth of planning research, pay attention to the evaluation of the implementation effect and benefit of individual projects, pay attention to solving the existing problems of power grid in a global perspective, avoid the point-to-point problem-solving thinking to plan power grid, and improve the comprehensive benefits of power grid planning and construction. Through the guidance of power network planning and rational layout of stations and network wiring, the utilization rate of power grid transmission and transformation equipment assets can be operated in a reasonable range. Within the framework of allowable cost of transmission and distribution price approval, we should formulate business management and control strategies for investment and assets, make cost planning, optimize cost structure and improve cost efficiency.

\subsection{Promoting communication and collaboration with the government}

Power grid companies should change the original concept of planning and independent decision-making, actively strengthen communication with relevant government departments, fully understand the needs and requirements of the government, and actively cooperate. In formulating grid planning standards and principles, we should consider not only the company's business development, but also the government's position and attitude. In carrying out grid planning research, we need to establish an effective coordination mechanism to strengthen communication. Communication and coordination with the government must run through the whole process of grid planning. Power grid companies should actively and deeply participate in the drafting and revision of the government's transmission and distribution price reform plan. By giving full play to the professional advantages, reasonable demands and suggestions are put forward on the basis of certain related research. At the same time, power grid companies should guide the formulation of relevant government programs. The ultimate goal is to reach agreement with the government on the objectives of power grid construction, planning technical principles and regulatory assessment standards. Power grid enterprises should also promote the establishment of a transmission and distribution price return mechanism based on effective assets to approve the total revenue of transmission and distribution, so as to ensure the sustainable development of the company. In short, power grid enterprises need to achieve the common goal of serving regional social and economic development.

\section{Conclusions}

This paper analyses the main problems faced by the company's investment planning in the new era. From the five aspects of power grid planning objectives, ideas, depth, effectiveness analysis and comprehensive management, it analyses the specific impact of power system reform on Guangzhou power grid investment planning. Based on the results of the study, the investment proposals for Guangzhou power grid planning are formulated, and the planning strategies for Guangzhou power grid are put forward, including improving the method of power grid planning, adjusting the idea of power grid planning, strengthening the guidance of asset efficiency, and promoting communication and cooperation with the government. Power grid companies should study the impact of new power reform in depth and adjust their investment planning strategies so as to enhance the competitiveness of enterprises.

\section{Acknowledgement}

This work was supported by State Grid Corporation Science and Technology Project (B3441318K002)

\section{References}

1. Y. He, Y. Ye, Q. Chen, Z. Yan, L. Yu, IOP Conference Series: Materials Science and Engineering, 439, 5 (2018)

2. D. Gao, T. Luo, P. Xin, Y.Wang, J. Lu, P. Cai, JPCS 1187,2 (2019)

3. X. Guo, P. Li, K. Zhan, W. Wei, Q. Tan, W. Yang, F. Luo, Energy Procedia, 145, 259(2018)

4. L. Bai, T. Jiang, F. Li, H. Chen, X. Li, $A P P L$ ENERG, 210, 1082(2018)

5. P.H. Jiao, J.J. Chen, B.X. Qi, Y.L. Zhao,K. Peng, INT J ELEC POWER, 107, 422(2019)

6. Q. Wu, C. Peng, Sustainability, 8, 796(2016) 